\title{
Hot stuff in the bushes: thermal imagers and the detection of fossorial burrows in vegetated sites
}

\author{
Tarnya Cox ${ }^{1}$, Robert Matthews ${ }^{2}$, Grant Halverson ${ }^{2}$, and Stephen Morris ${ }^{3}$ \\ ${ }^{1}$ NSW Department Primary Industries \\ ${ }^{2}$ Affiliation not available \\ ${ }^{3}$ New South Wales Department of Primary Industries
}

September 16, 2020

\begin{abstract}
1. 1. Thermal imaging technology is a developing field in wildlife management. Most thermal imaging work in wildlife science has been limited to larger ungulates and surface-dwelling mammals. Little work has been undertaken on the use of thermal imagers to detect fossorial animals and/or their burrows. Survey methods such as white-light spotlighting can fail to detect the presence of burrows (and therefore the animals within), particularly in areas where vegetation obscures burrows. Thermal imagers offer opportunity to detect the radiant heat from these burrows, and therefore the presence of the animal, particularly in vegetated areas. Thermal imaging technology has become increasingly available through the provision of smaller, more costeffective units. Their integration with drone technology provides opportunities for researchers and land managers to utilise this technology in their research/management practices. 2. We investigated the ability of both consumer (AUD\$65,000) mounted on drones to detect rabbit burrows (warrens) and entrances in the landscape as compared to visual assessment. 3. Both types of imager and visual inspection detected active rabbit warrens when vegetation was scarce. The presence of vegetation was a significant factor in detecting entrances $(\mathrm{P}<0.001, \alpha=0.05)$. The consumer imager did not detect as many warren entrances as either the professional imager or visual inspection $(\mathrm{P}=0.009, \alpha=0.05)$. Active warren entrances obscured by vegetation could not be accurately identified on exported imagery from the consumer imager and several false-positive detections occurred when reviewing this footage. 4. We suggest that the exportable $\mathrm{Hz}$ rate was the key factor in image quality and subsequent false positive detections. This feature should be considered when selecting imagers. Thermal imagers are a useful additional tool to aid in identification of entrances for active warrens and professional imagers detected more warrens and entrances than either consumer imagers or visual inspection.
\end{abstract}

\section{Key-words}

thermal imager, drone, warrens, UAV, remote detection, survey, pest animals

\section{Introduction}

Since its development, thermal imaging technology was predominantly used in industrial applications. It was regularly used in construction fields to measure heat flow, identify structural defects (Grinzato, Vavilov et al. 1998, Balaras and Argiriou 2002), detect gas leaks, for powerline maintenance and for the management of forest fires. More recently, applications ranged from determining the structural features of volcanoes (Harris 2013), to medical applications such as detection of breast cancer (Mostovoy 2008, Ng 2009) and monitoring of pain (Agarwal, Spyra et al. 2008), (see (Vollmer and Möllmann 2018) for a full review of the use of thermal imaging across study areas).

Thermal imaging technologies were increasingly used in wildlife surveys from the 1960s (see (Croon, McCullough et al. 1968, Parker and Driscoll 1972)) although their widespread use has been limited due to the 
cost of the equipment and a lack of exposure of this type of equipment to biologists. The majority of wildlife survey work undertaken with thermal technology was in the detection of large wild animals such as pigs and ungulates using fixed or rotary wing aerial survey techniques (and occasionally comparing these results to visual surveys over the same area) (Parker and Driscoll 1972, Havens and Sharp 1998, Focardi, De Marinis et al. 2001). Limited work has been done on abundance estimates of smaller animals and the detection of fossorial animals and/or their burrows with thermal imagers (Boonstra, Krebs et al. 1994). Burrows of fossorial animals can be difficult to detect with more traditional white-light spotlighting used during ground surveys, particularly where vegetation is present. Additionally, those burrows that can be found often give little and subjective indication as to whether that burrow is occupied.

The detection of occupied burrows is particularly important when the burrowing animal is a pest, such as rabbits (Oryctolagus cuniculus ) in Australia. Rabbits are a significant agricultural and environmental pest and are listed as a key threatening process (Commonwealth of Australia 2016). Rabbits were estimated to cause >AUD $\$ 206$ million per annum in agricultural losses (Gong, Sinden et al. 2009). Additionally, it was estimated that private and public landholders spend approximately AUD $\$ 6$ million per annum controlling rabbits. They are listed as a direct threat for 321 species of Australian plants and animals and 75 endangered ecological communities (Commonwealth of Australia 2016). The most effective long-term method of controlling rabbits is the removal of their harbour. Usually this means the destruction of their burrow (hereafter referred to as a warren) through ripping programs, however, the success of ripping programs is greatly influenced by the presence of surrounding active warrens (McPhee and Butler 2010). Reopening of ripped warrens can occur if any nearby warrens remain intact, therefore it is essential that all warrens and warren entrances within the treatment area are located. Where rabbit numbers are high $(>5$ rabbits $/ \mathrm{Ha})$, warrens can be easy to locate due to the lack of vegetative cover. However, where numbers are lower, or non-palatable plants are abundant, warren entrances can be obscured and difficult to find.

Thermal imagers may provide a way to detect these obscured rabbit warrens. Boonstra et al (1994) used thermal imagers to differentiate between occupied and unoccupied arctic ground squirrel (Urocitellus parryii ) burrows (where the location of the burrow was known). They also identified that the presence of dense vegetation was a limiting factor in thermal surveys. Technological development of thermal imagers has progressed rapidly over the last 10 years, and there is a proliferation of thermal imagers available for consumers. Therefore, we felt it time to re-evaluate thermal imagers for the detection of animal burrows. We investigated whether consumer thermal imagers could be used as a tool to assist land managers with identifying rabbit warrens, particularly if obscured by vegetation. Here we investigate the use of thermal imagers to 1) determine whether active and inactive rabbit warrens could be detected with a thermal imager, and (if so) 2) to evaluate the efficacy of consumer imagers to professional imagers and visual inspection.

\section{Materials and Methods}

\section{Site locations}

The evaluation took place in two parts over three properties in New South Wales, Australia. Part 1 was undertaken on two private properties in the Central Tablelands in November 2017. Part 2 occurred on public land in the Central West in June2018. We classified the rabbit populations at each of these locations as very high ( $>10$ rabbits/Ha), high ( $>5$ rabbits/Ha), medium $(2-5$ rabbits/Ha) and low $(<2$ rabbits/Ha) using standard white-light spotlight counts (Mitchell and Balogh 1996). For Part 1, one property was overgrazed, had little-to-no vegetation and a very high population of rabbits. The other property was a disused stock paddock that contained stands of blackberry (Rubus fruticosus species aggregate) on the gully lines and was overrun with serrated tussock (Nassella trichotoma). This property had a low rabbit population. Rabbit warrens on these two properties had an average depth of $600-800 \mathrm{~mm}$ and we surveyed five warrens at each property. For Part 2 the land was part of the national travelling stock route (authorised thoroughfare for the walking of domestic livestock from one location to another across Australia) and at the time of the survey consisted of open sandy country with stands of Old Man Saltbush (Atriplex nummularia). The average rabbit warren depth was $1500-2500 \mathrm{~mm}$ and the rabbit population was classified as very high. We surveyed 
a 6.11 Ha portion of the area.

\section{Equipment used}

We used three uncooled microbolometer arrays (Table 1) of varying sensor size and cost. The Jenoptik VarioCAM HD (hereafter referred to as the "Jenoptik") professional thermal imager was used to evaluate part 1, with the FLIR Zenmuse XT640 and Sierra-Olympic VayuHD used in part 2 (hereafter referred to as the "Zenmuse" and "Vayu" respectively). The Zenmuse came as an integrated system with the DJI Inspire 1 drone, however, both the Jenoptik and the Vayu were heavier non-integrated imagers. Both imagers required mounting to a Ronin MX gimbal (https://www.dji.com/au/ronin-mx) for image stabilisation. The Jenoptik was mounted to a DJI S1000+ drone (https://www.dji.com/au/spreading-wings-s1000/spec )and the Vayu mounted to a DJI Matrice 600 drone (https://www.dji.com/au/matrice600/info\#specs). All video was collected and processed as "white-hot" grayscale imagery.

Table 1: The three thermal imagers (uncooled microbolometer arrays) used during the study. The Jenoptik VarioCAM HD was used to evaluate whether rabbit warrens could be detected by a thermal imager. The FLIR Zenmuse XT640 and Sierra-Olympic VayuHD were used to compare consumer products with high-end professional products. The FLIR Zenmuse XT640 came as an integrated system with the DJI Inspire I drone. ( $\mathrm{Hz}=$ frame rate).

\begin{tabular}{|c|c|c|c|c|c|c|c|}
\hline Imager & Drone & $\mathrm{Hz}$ (view) & $\begin{array}{l}\mathrm{Hz} \\
\text { (export) }\end{array}$ & $\begin{array}{l}\text { Sensor (w } \\
\mathrm{x} \mathrm{h}) \mathrm{mm}\end{array}$ & $\begin{array}{l}\text { Image (w } x \\
\text { h) px }\end{array}$ & Pixel pitch & $\begin{array}{l}\text { Cost } \\
\text { (\$AUD) }\end{array}$ \\
\hline $\begin{array}{l}\text { FLIR } \\
\text { Zenmuse }\end{array}$ & $\begin{array}{l}\text { DJI } \\
\text { Inspire } 1\end{array}$ & 30 & $<9$ & $\begin{array}{l}12.38 \mathrm{x} \\
9.68\end{array}$ & $640 \times 512$ & $17 \mu \mathrm{m}$ & $\begin{array}{l}\sim \text { AUD } \$ 20 \mathrm{~K} \\
\text { (integrated) }\end{array}$ \\
\hline $\begin{array}{l}\text { XT } 640 \\
\text { Jenoptik } \\
\text { Vario- } \\
\text { CAM } \\
\text { HD }\end{array}$ & DJI M600 & 30 & 30 & $17.4 \times 13.5$ & $1024 \times 800$ & $17 \mu \mathrm{m}$ & $\begin{array}{l}\sim \text { AUD } \$ 80 \mathrm{~K} \\
\text { (imager } \\
\text { only) }\end{array}$ \\
\hline $\begin{array}{l}\text { Sierra- } \\
\text { Olympic } \\
\text { VayuHD }\end{array}$ & DJI M600 & 30 & 30 & $24 \times 14.5$ & $1920 \times 1200$ & $12 \mu \mathrm{m}$ & $\begin{array}{l}\sim \text { AUD } \$ 170 \mathrm{~K} \\
\text { (imager } \\
\text { only) }\end{array}$ \\
\hline
\end{tabular}

\section{Warren surveys}

All surveys were conducted in the morning before first light to maximise the temperature differential between warren entrances and the surrounding terrain. All sites were visually inspected for rabbit warrens (active and inactive) on foot during the day and all identified warrens were mapped with their GPS locations recorded. In Part 1 we determined whether active rabbit warrens could be detected with a thermal imager. We flew the drone with the Jenoptik imager directly to the warren locations. In Part 2 we compared a professional imager (Vayu) to a consumer imager (Zenmuse). We established parallel flight transects to allow complete coverage of the area being investigated and to mimic the actual survey method that should be employed to search for warrens. We undertook visual counts of warrens and warren entrances in Part 2. Visual counts were undertaken upon arrival and before the drone flights. Parallel line transects approximately $10 \mathrm{~m}$ apart were walked and all warrens and associated entrances were recorded. Once imagery from the drone flights was processed (see below), we undertook an additional visual inspection on foot to confirm entrances identified from the thermal imagery and to identify any false-positives or -negatives.

Data cleaning and statistical analysis

We downloaded the footage from the thermal imagers to an external hard drive and reviewed the footage from this drive using VLC media player 3.0.8. We recorded observations in a custom-built Microsoft Excel (Microsoft Corporation 2018) workbook which utilised the drone's tracklog to georeference observation locations. This file was then exported as a KML file and viewed in Google Earth Pro (Google Earth Pro 2019) 
to aid in comparison between thermal imager and visual inspection detections.

Where transect imagery overlapped, double observations of warren entrances were removed. If a warren complex was identified on one transect, and additional warren entrances were identified on the immediate next transect in the same location, then a determination was made on whether these entrances belonged to the same warren or constituted a new warren. This ensured warren counts were not over-estimated.

Warrens were classified by the amount of vegetation present that was likely to obscure entrances. Warrens with no vegetation present were classified as "open", warrens obscured by vegetation (e.g. entrances were beneath shrubs) were classified as "vegetated" and warrens that had entrances in the open and obscured by vegetation were classified as "mixed". These classifications also applied to the entrances associated with that warren for analysis (i.e. individual entrances in "mixed" warrens were not further classified into "open" or "vegetated" categories for analysis).

\section{Statistical analysis}

We used the lme4 (Bates, Maechler et al. 2015) andlmerTest (Kuznetsova, Brockhoff et al. 2017) packages in R (R Core Team 2019) to test for any difference in entrance count associated with imager. We used a mixed model with Poisson likelihood to account for the nested structure of imagers within warrens and the contrast of vegetation class between distinct warren sets. Package emmeans (Lenth 2019) was used to inspect the mean entrance count under each vegetation and imager class. Additionally, we plotted difference between estimates vs average of the estimates to check for any patterning in case agreement depended on magnitude of observation as suggested by Altman and Bland (1983). To address any disagreement in terms of presence or absence of entrances detected, the three pairings of methods (visual vs Vayu, visual vs Zenmuse and Vayu vs Zenmuse) were examined by classifying entrance counts as equal to or greater than zero and forming two-way tables (Table 2).

Table 2: two-way table used to quantify agreement (proportion of warrens where the imagers agree on presence or absence of warrens), False Nil (the proportion of warrens where imager "1" detected entrances but imager "2" detected zero entrances) and False Presence (The proportion of warrens where imager "1" detected zero entrances but imager " 2 " detected at least 1 entrance).

\begin{tabular}{lll}
\hline & Imager 1 Nil & Imager 1 Present \\
\hline Imager 2 Nil & $a$ & $b$ \\
Imager 2 Present & $c$ & $d$ \\
\hline
\end{tabular}

Ratios of the table cells to the marginal totals can then be used to quantify:

Agreement: The proportion of warrens where the imagers agree on presence or absence of warrens.

$$
\frac{a+d}{a+b+c+d}
$$

False Nil: The proportion of warrens where imager "1" detected entrances but imager "2" detected zero entrances.

$$
\frac{b}{b+d}
$$

False Presence: The proportion of warrens where imager "1" detected zero entrances but imager "2" detected at least 1 entrance.

$$
\frac{c}{a+c}
$$


Note that the word "false" here is a value judgment given the arbitrary decision of which imager to designate as "1". However, use of "visual" as the baseline to compare the performance of the thermal imagers seems justifiable. For all analysis the significance level was set at 0.05 .

\section{Results}

\section{Part 1 - Detecting rabbit warrens}

Active rabbit warrens were detected via thermal imagery in both high-density and low-density areas (Fig. 1) using the Jenoptik. Rabbit warren entrances were detected under vegetation, including under blackberry (Fig. 1b) and where they were obscured by serrated tussock. No inactive rabbit warrens were detected by any of the thermal imagers during this study.
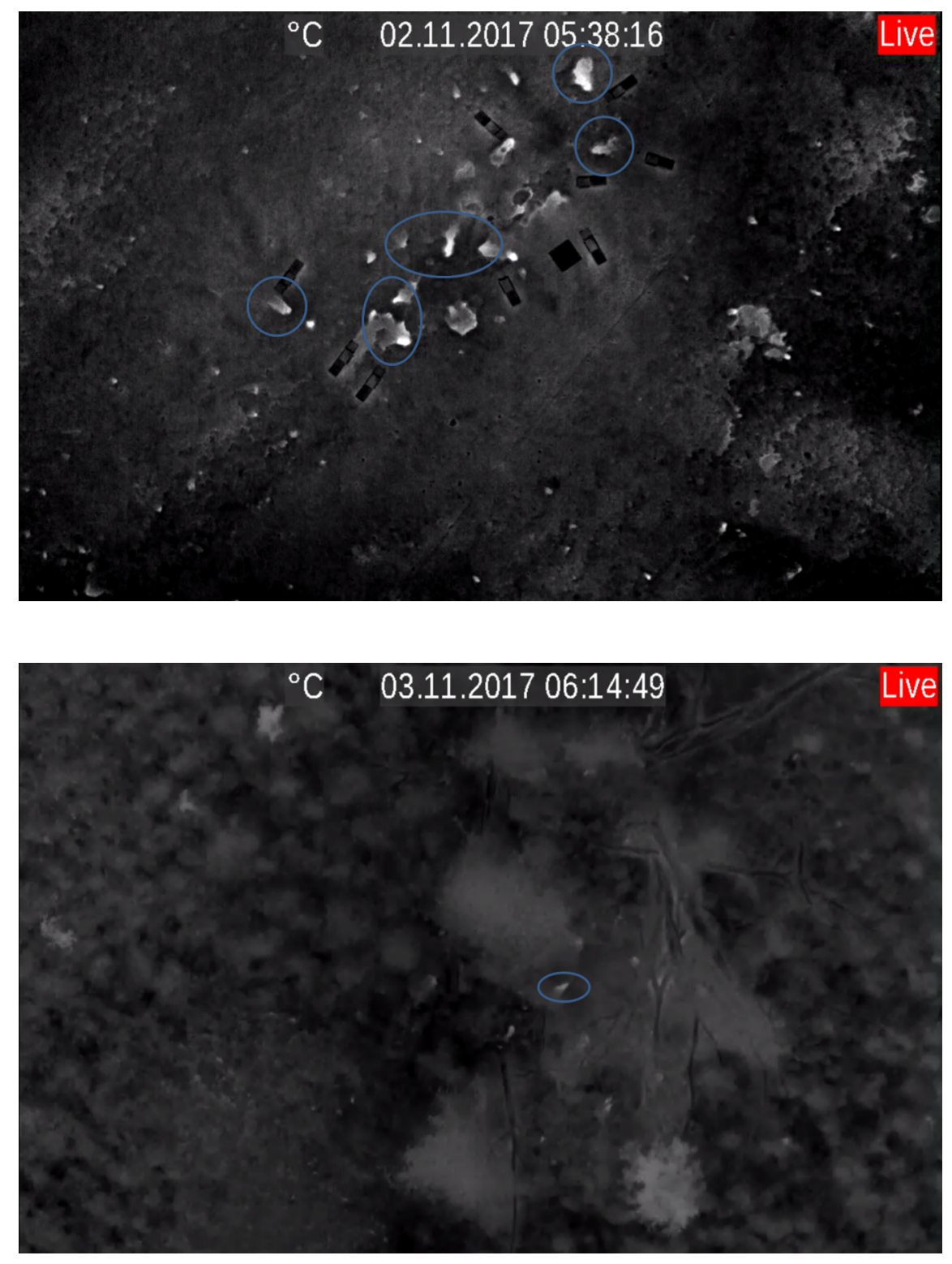

Figure 1: Active rabbit warrens detected by a thermal imager (Jenoptik VarioCAM HD) in (left) a highdensity area with little vegetation, and (right) a low-density area with extensive stands of serrated tussock 
and blackberry. Blue circles highlight some of the rabbit warren entrances.

Part 2 - Evaluation of imagers and visual inspections

Vegetation was a significant factor in the detection of rabbit warrens $(p=<0.001)$. There were 22 warrens present within the survey area. All warrens identified by visual assessment $(n=14)$ were identified in the imagery from the Vayu. Three warrens identified by visual assessment were not identified in the Zenmuse footage. However, both the Zenmuse and the Vayu detected more rabbit warrens and entrances than visual inspection (Table 3, Fig. 2a). A pairs plot shows the correlation between counts under each imager over all vegetation classes (1:1 lines added to show agreement, Fig. 3). The methods seem broadly in agreement. The Zenmuse detected significantly more entrances than both visual inspection and the Vayu $(\mathrm{P}=0.049)$. Several entrances and warrens detected using the Zenmuse were later visually identified as false positives ( $\mathrm{n}=21$ entrances, $\mathrm{n}=19$ warrens) (Fig. 2b). The Vayu detected active warrens beneath vegetation and detected more warrens than visual inspection (Fig. 2d, Table 3) with no false positives. Only 10 of the 22 warrens were detected by all three methods (Vayu, visual and Zenmuse), and 13 of the 22 were detected by both the Vayu and visual inspection. Two warrens were detected by thermal imager (both types) that were not detected by visual inspection with an additional four warrens (three single and one four-entrance warren) only detected by the Vayu (see Appendix).

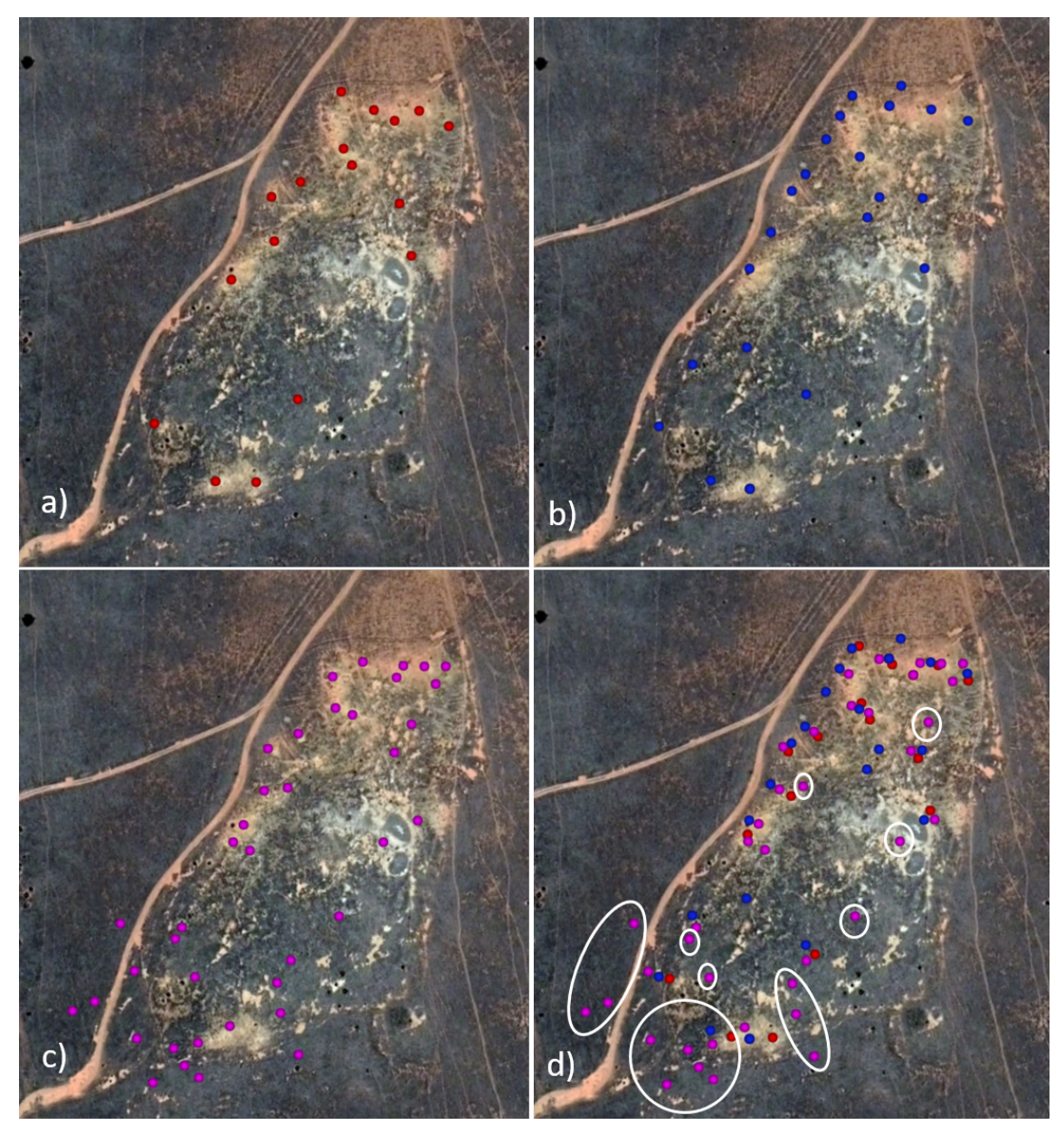

Figure 2: The locations of warrens detected by a) visual assessment, b) with the Vayu, c) with the Zenmuse (false-positive detections circled in white - pink dots only), and d) a comparison of all detections from all 
three methods (with the false positives from the Zenmuse removed). The Zenmuse had a high rate of false-positive imagery.
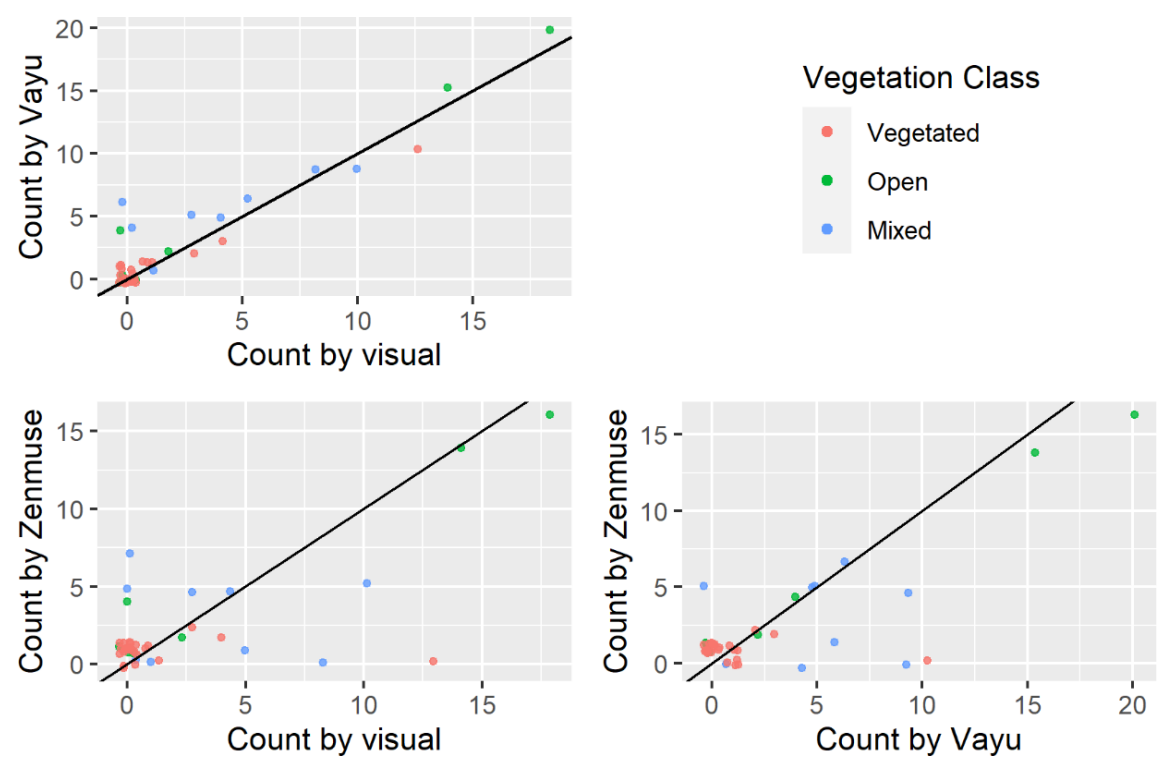

Figure 3: A pairs plots showing the correlation between counts under each imager or detection type (visual inspection, Vayu and Zenmuse) over all vegetation classes. 1:1 lines are added to show agreement and white noise added to each point in order to reveal over-strikes.

Table 3: The number of warrens and entrances detected by each inspection method (Visual, Vayu, and Zenmuse $)$ in each habitat type $(\mathrm{O}=$ open, $\mathrm{M}=$ mixed, $\mathrm{V}=$ vegetated $)$.

\begin{tabular}{llllll}
\hline & Number detected & Number detected & Number detected & Number detected & Nu \\
& Entrances & Entrances & Entrances & Entrances & Wa \\
Imager/Detection type & $\mathbf{O}$ & $\mathbf{M}$ & $\mathbf{V}$ & Total & $\mathbf{O}$ \\
Visual & 34 & 31 & 22 & $\mathbf{8 7}$ & 3 \\
Vayu & 50 & 45 & 22 & $\mathbf{1 1 7}$ & 4 \\
Zenmuse & 28 & 22 & $\mathbf{8 9}$ & 7 \\
\hline
\end{tabular}

Inspection of the mean entrance count under each vegetation and imager class (Table 4) revealed that, on average, both imager types and visual inspection detected almost the same number of entrances in open and vegetated areas. In mixed areas the Vayu detected, on average, one more entrance per warren than visual inspection and twice as many entrances per warren than the Zenmuse.

Table 4: Mean entrance count for each imager/detection type under each vegetation type. Confidence level used: 0.95 . Intervals are back transformed from the log scale.

\begin{tabular}{llllll}
\hline Vegetation & Imager & Rate & SE & LCL & UCL \\
\hline Open & Visual & 2.027 & 0.897 & 0.851 & 4.828 \\
& Vayu & 2.445 & 1.068 & 1.038 & 5.757 \\
\multirow{5}{*}{ Vegetated } & Zenmuse & 2.325 & 1.019 & 0.985 & 5.491 \\
& Visual & 0.528 & 0.164 & 0.287 & 0.973 \\
& Vayu & 0.505 & 0.159 & 0.273 & 0.936 \\
& Zenmuse & 0.505 & 0.159 & 0.273 & 0.936
\end{tabular}




\begin{tabular}{llllll}
\hline Vegetation & Imager & Rate & SE & LCL & UCL \\
\hline Mixed & Visual & 2.776 & 1.057 & 1.317 & 5.854 \\
& Vayu & 4.030 & 1.480 & 1.962 & 8.276 \\
& Zenmuse & 2.507 & 0.966 & 1.179 & 5.334 \\
\hline
\end{tabular}

Although the imagers were in agreement with respect to average entrance count over the survey, it is clear from Fig. 3 that there is a degree of disagreement in terms of presence or absence of entrances detected. Output from the contingency tables (Table 5) show that the visual and Vayu had agreement on presence or absence of entrances on $83 \%$ of warrens, noting that the Vayu detected entrances where the visual had not on $27 \%$ of warrens (Table 6). The Zenmuse was in poor agreement with the visual (27\%) and Vayu (34\%) and it seems the Zenmuse was particularly prone to detecting warrens that were "false positives" when compared to visual (85\%) and Vayu (100\%) (Table 6).

Table 5: Contingency tables for the three pairings of methods (visual vs Vayu, visual vs Zenmuse and Vayu vs Zenmuse) using classification of entrance counts as equal to or greater than zero.

\begin{tabular}{lll}
\hline & Visual Nil & Visual Present \\
\hline Vayu Nil & 19 & 0 \\
Vayu Present & 7 & 15 \\
& Visual Nil & Visual Present \\
Zenmuse Nil & 4 & 4 \\
Zenmuse Present & 22 & 11 \\
& Vayu Nil & Vayu Present \\
Zenmuse Nil & 0 & 8 \\
Zenmuse Present & 19 & 14 \\
\hline
\end{tabular}

Table 6: Outputs from contingency tables for the three pairings of methods (visual vs Vayu, visual vs Zenmuse and Vayu vs Zenmuse) quantifying agreement (proportion of warrens where the imagers agree on presence or absence of warrens), False Nil (the proportion of warrens where imager "1" detected entrances but imager "2" detected zero entrances) and False Presence (The proportion of warrens where imager "1" detected zero entrances but imager "2" detected at least 1 entrance) between the methods.

\begin{tabular}{llllll}
\hline & $\mathbf{x}$ & $\mathbf{n}$ & Mean & LCL & UCL \\
\hline Visual vs Vayu & & & & & \\
Agreement & 34 & 41 & 0.83 & 0.68 & 0.93 \\
False Nil & 0 & 15 & 0.00 & 0.00 & 0.22 \\
False Presence & 7 & 26 & 0.27 & 0.12 & 0.48 \\
Visual vs Zenmuse & & & & & \\
Agreement & 15 & 41 & 0.37 & 0.22 & 0.53 \\
False Nil & 4 & 15 & 0.27 & 0.08 & 0.55 \\
False Presence & 22 & 26 & 0.85 & 0.65 & 0.96 \\
Vayu vs Zenmuse & & & & & \\
Agreement & 14 & 41 & 0.34 & 0.20 & 0.51 \\
False Nil & 8 & 22 & 0.36 & 0.17 & 0.59 \\
False Presence & 19 & 19 & 1.00 & 0.82 & 1.00 \\
\hline
\end{tabular}

\section{Discussion}


We believe this is the first study of its kind to show that thermal imagers can be used in systematic surveys to detect previously unknown burrows of fossorial animals. All three thermal imagers tested could detect active rabbit warrens. Both professional imagers could detect active rabbit warrens that were either obscured by, or under, vegetation, including blackberry bushes. The Vayu detected five more warrens in vegetated areas, three more warrens and 14 more warren entrances in mixed vegetation and 16 more entrances in open areas than visual inspection. The Zenmuse initially appeared to detect more warrens and warren entrances than any other method, particularly in vegetated areas, however, inspection of these detections revealed a high number of false positives.

The Vayu, Zenmuse and visual inspection detected the same number of entrances in vegetated habitat (Table 2 ), but the Vayu detected twice as many warrens, particularly single-entrance warrens. Single entrance warrens may indicate a breeding stop or can be the start of a new warren. Either way, these single entrance warrens are important features to manage during a control program.

The professional imagers had far superior exported imagery resulting in no false-positive detections of rabbit warren entrances during post-survey processing. We suspect that it is the exportable frame rate $(\mathrm{Hz})$ that contributed to the poor performance of the Zenmuse. This lower-quality imagery made it difficult to distinguish between single warren entrances and other hot material such as rocks, which effectively looked like "hot blobs". These "hot blobs" had little definition which made identification difficult. The viewing rate of the live stream from the imager $(30 \mathrm{~Hz})$ was enough to see rabbit warrens as the drone was flying, yet the exported video file at $<9 \mathrm{~Hz}$ resulted in poor quality blurred imagery that was unsuitable for postsurvey analysis. Given that this technology is likely to be used to survey an area and have the imagery post-processed and geo-tagged so that warrens can be mapped and subsequently removed, the lower export frame rate of $<9 \mathrm{~Hz}$ of these imagers is insufficient for the task. These issues did not exist for the professional imagers which both had an export frame rate of $30 \mathrm{~Hz}$. Consumers can overcome the low export frame rate through the addition of an external high-speed recorder to record the feed from the imager at the viewing frame rate. This will add additional cost to the setup, but this cost is insignificant compared to that of professional imagers.

Detecting active warrens and entrances gave no indication of the number of animals' present. The use of thermal imagers to estimate rabbit abundance in these scenarios is unreliable and not recommended. This technique provides presence data only. It is unknown how many rabbits are required to generate a heat signature at an entrance. Boonstra et al (1994) and Hubbs et al (2000) used thermal imaging to estimate the average number of hot entrances per arctic ground squirrel and then estimated abundance. Theoretically, the same should be possible for rabbits. However, factors such as warren size (number of entrances), warren depth and even soil type are likely to influence the thermal signatures from entrances. Additionally, how many rabbits are required to generate a heat signature in a variety of these conditions needs to be understood. Further research should include the removal of all rabbits from warrens of varying depths in varying soil types to determine the minimum number of rabbits required to emit a detectable heat signature.

Thermal imaging technology is becoming more widely available but is still a costly technique. However, the cost of missing warren entrances in a ripping program may be greater. The opportunity for rabbits to re-open warrens through missed entrances has the potential to negate tens-of-thousands of dollars of work on a local scale and millions of dollars on the national scale. Australians spend approximately AUD\$6 million per year on rabbit control programs (Gong, Sinden et al. 2009), and many programs include warren ripping. Warren ripping can cost anywhere from AUD $\$ 50-\$ 150$ per hectare, depending on the size of the equipment used, the level of infestation and the soil type. For our survey area in western NSW, we estimated that ripping would cost AUD $\$ 1200-1800$ for the $6 \mathrm{Ha}$ given the very high rabbit population. Ripping programs tend not to happen in isolation and they are often part of a multi-tool approach with associated poisoning programs (approx. AUD $\$ 50 / \mathrm{Ha}$ ) at a minimum. This brings the cost of initial control for these $6 \mathrm{Ha}$ to AUD $\$ 1500-\$ 2100$. Rabbits from surrounding areas can quickly reinvade and repopulate these $6 \mathrm{Ha}$ if all the warrens and entrances are not detected (McPhee and Butler 2010). The professional imager detected 30 more entrances and eight more warrens overall than visual inspection or the corrected consumer imager. If 
warren ripping was undertaken at this site using the visual or corrected consumer imager data alone, then up to eight warrens could have been missed, rendering the control program ineffective. The next active warren was only $150 \mathrm{~m}$ outside of these $6 \mathrm{Ha}$. If we assume this is the same in all directions, then approximately 6 out of every 15Ha's would require treatment. Repeated across warrens on average small holdings (30-100Ha), the cost of missed warrens/entrances and having to repeat control programs soon becomes considerable.

While this research focuses on the detection of active rabbit warrens and their entrances, the inadequacies of the exported imagery from the consumer imager will be important in other areas of thermal research. We expect that professional grade thermal imagers will not be widely used in many wildlife research projects simply due to their cost. However, as consumer grade thermal imaging equipment becomes increasingly available, there is an opportunity to incorporate thermal imagery more cost-effectively into ecology research projects. More information needs to be gathered on how these consumer grade thermal imagers perform in detecting a range of wildlife species. In particular, how the low exportable Frame rate affects post-flight image processing and the occurrence of "hot blobs" and species identification.

\section{Conclusions}

Thermal imaging technology provides an efficient method for detecting rabbit warrens and entrances in all vegetation types (open, vegetated and mixed), surpassing the use of visual inspection alone. Improved detection of warrens and their entrances can lead to more effective control programs, ensuring all warrens and entrances within an area are identified. This should lead to reduced control costs over time due to decreased rates of reopening. Both consumer and professional thermal imagers can be used, however, consumer imagers should be supplemented with additional technology due to their poor exportable Frame rate. Low exportable Frame rates produce noisy and blurred imagery. This causes hot spots to look like indistinguishable white blobs which ultimately results in a high number of false-positive detections.

\section{Acknowledgements}

This work was made possible with the assistance of Suzy Holbery from Riverina Local Land Services who identified rabbit-prone areas in Hay, New South Wales; property owners Geoff Morris (Windella) and Lesley Press (Oaky Creek) for access to their properties, and Melissa Snape from Australian Capital Territory Government for the loan of the DJ Inspire I integrated drone and Zenmuse XT640. We would also like to thank Bernie Dominiak and 2 anonymous reviewers for providing comments on this manuscript. This work was funded through the Australian Commonwealth Government's Control tools and technologies for established pest animals and weeds competitive grants program 2017 and was completed with animal ethics approval (Orange AEC - ORA 18/21/021). The authors declare no conflict of interest.

\section{Authors contribution statement}

TC conceived the ideas, TC, RM and GH designed methodology, RM and GH collected the data, TC and SM analysed the data and TC led the writing of the manuscript. TC, RM and SM contributed critically to the drafts and gave final approval for publication.

\section{Data Availability Statement}

The data used in the analysis is available in the supplementary material. The original thermal footage is the property of the New South Wales Department of Primary Industries. To discuss access please email the corresponding author.

\section{References}

Agarwal, K., P.-S. Spyra and H. E. Beck (2008). Monitoring effects of sympathicolysis with infraredthermography in patients with complex regional pain syndromes (CRPS). Inframation 2008.

Altman, D. G. and J. M. Bland (1983). "Measurement in Medicine: The Analysis of Method Comparison Studies." Journal of the Royal Statistical Society. Series D (The Statistician) 32 (3): 307-317. 
Balaras, C. A. and A. A. Argiriou (2002). "Infrared thermography for building diagnostics." Energy and Buildings 34 (2): 171-183.

Bates, D., M. Maechler, B. Bolker and S. Walker (2015). "Fitting Linerar Mixed-Effects Models using lme4." Journal of Statistical Software67 (1): 1-48.

Boonstra, R., C. J. Krebs, S. Boutin and J. M. Eadie (1994). "Finding Mammals Using Far-Infrared Thermal Imaging." Journal of Mammalogy75 (4): 1063-1068.

Commonwealth of Australia (2016). Threat abatement plan for competition and land degradation by rabbits.

Croon, G. W., D. R. McCullough, C. E. Olson and L. E. Queal (1968). "Infrared scanning techniques for big game censusing." Journal of Wildlife Management 32 : 751-759.

Focardi, S., A. M. De Marinis, M. Rizzotto and A. Pucci (2001). "Comparative evaluation of thermal infrared imaging and spotlighting to survey wildlife" Wildlife Society Bulletin 29 (1): 133-139.

Gong, W., J. Sinden, M. Braysher and R. Jones (2009). The Economic Impact of Vertebrate Pests in Australia. Final Report on Project IACRC 12 D. Canberra, IA CRC.

Google Earth Pro (2019). Hay Plains, -34.431228 144.845285, 89m . Image date: 16 November 2018

Grinzato, E., V. Vavilov and T. Kauppinen (1998). "Quantitative infrared thermography in buildings." Energy and Buildings 29 (1): 1-9.

Harris, A. (2013). Thermal remote sensing of active volcanoes: a user's manual. Cambridge, United Kingdom, Cambridge University Press.

Havens, K. J. and E. J. Sharp (1998). "Using thermal imagery in the aerial survey of animals." Wildlife Society Bulletin 26 (1): 5-16.

Hubbs, A. H., T. Karels and R. Boonstra (2000). "Indices of Population Size for Burrowing Mammals." The Journal of Wildlife Management64 (1): 296-301.

Kuznetsova, A., P. B. Brockhoff and R. H. B. Christensen (2017). "ImerTest Package: Tests in Linear Mixed Effects Models." Journal of Statistical Software 82 (13): 1-26.

Lenth, R. (2019). emmeans: Estimated Marginal Means, aka Least-Squares Means. R package version 1.4.

McPhee, S. R. and K. L. Butler (2010). "Long-term impact of coordinated warren ripping programmes on rabbit populations." Wildlife Research37 (1): 68-75.

Microsoft Corporation, 2018. Microsoft Excel. Available at: https://office.microsoft.com/excel.

Mostovoy, A. (2008). Breast thermography and clinical applications. Inframation 2008.

Ng, E. Y.-K. (2009). "A review of thermography as a promising non-invasive detection modality for breast tumor." International Journal of Thermal Sciences $48:$ 849-859.

Parker, H. D. J. and R. S. Driscoll (1972). "An experiment in deer detection by thermal scanning." Journal of Rangeland Management25 : 480-481.

R Core Team (2019). R: A language and environment for statistical computing. R Foundation for Statistical Computing. Vienna, Austria.

Vollmer, M. and K. P. Möllmann (2018). Infrared Thermal Imaging: fundamentals, research and applications. Second Edition. Weinheim, Germany, Wiley-VCH.

Appendix

List of warrens, vegetation type and number of warren entrances detected by each detection method/imager type. Grey rows indicate false positive detections from the Zenmuse footage. 


\begin{tabular}{|c|c|c|c|c|}
\hline & & Number of entrances detected & Number of entrances detected & Number of entrances detected \\
\hline vegetation & warren & visual & vayu & zenmuse \\
\hline $\mathrm{v}$ & $\mathrm{A}$ & 0 & 0 & 1 \\
\hline $\mathrm{v}$ & $\mathrm{B}$ & 0 & 0 & 1 \\
\hline $\mathrm{v}$ & $\mathrm{C}$ & 0 & 0 & 1 \\
\hline $\mathrm{m}$ & $\mathrm{D}$ & 1 & 1 & 0 \\
\hline $\mathrm{m}$ & $\mathrm{E}$ & 0 & 6 & 7 \\
\hline $\mathrm{v}$ & $\mathrm{F}$ & 0 & 1 & 0 \\
\hline $\mathrm{v}$ & $\mathrm{G}$ & 3 & 2 & 2 \\
\hline $\mathrm{m}$ & $\mathrm{H}$ & 4 & 5 & 5 \\
\hline $\mathrm{m}$ & I & 10 & 9 & 5 \\
\hline o & $\mathrm{J}$ & 18 & 20 & 16 \\
\hline $\mathrm{v}$ & $\mathrm{K}$ & 0 & 1 & 1 \\
\hline $\mathrm{v}$ & $\mathrm{L}$ & 0 & 0 & 1 \\
\hline $\mathrm{v}$ & M & 4 & 3 & 2 \\
\hline $\mathrm{v}$ & $\mathrm{N}$ & 0 & 0 & 1 \\
\hline $\mathrm{v}$ & $\mathrm{O}$ & 0 & 0 & 1 \\
\hline $\mathrm{v}$ & $\mathrm{P}$ & 0 & 1 & 0 \\
\hline o & $\mathrm{Q}$ & 0 & 0 & 1 \\
\hline o & $\mathrm{R}$ & 14 & 15 & 14 \\
\hline o & $\mathrm{S}$ & 2 & 2 & 2 \\
\hline $\mathrm{m}$ & $\mathrm{T}$ & 0 & 4 & 0 \\
\hline $\mathrm{m}$ & $\mathrm{U}$ & 8 & 9 & 0 \\
\hline $\mathrm{v}$ & $\mathrm{V}$ & 1 & 1 & 0 \\
\hline $\mathrm{v}$ & W & 0 & 1 & 0 \\
\hline $\mathrm{v}$ & $\mathrm{X}$ & 13 & 10 & 0 \\
\hline $\mathrm{v}$ & $\mathrm{Y}$ & 0 & 0 & 1 \\
\hline $\mathrm{v}$ & $\mathrm{Z}$ & 0 & 0 & 1 \\
\hline $\mathrm{v}$ & $\mathrm{AA}$ & 0 & 0 & 1 \\
\hline $\mathrm{v}$ & $\mathrm{AB}$ & 0 & 0 & 1 \\
\hline $\mathrm{v}$ & $\mathrm{AC}$ & 0 & 0 & 1 \\
\hline o & $\mathrm{AD}$ & 0 & 4 & 4 \\
\hline $\mathrm{v}$ & $\mathrm{AE}$ & 1 & 1 & 1 \\
\hline $\mathrm{v}$ & $\mathrm{AF}$ & 0 & 0 & 1 \\
\hline $\mathrm{v}$ & $\mathrm{AG}$ & 1 & 1 & 1 \\
\hline $\mathrm{m}$ & $\mathrm{AH}$ & 0 & 0 & 5 \\
\hline o & $\mathrm{AI}$ & 0 & 0 & 1 \\
\hline $\mathrm{m}$ & AJ & 3 & 5 & 5 \\
\hline $\mathrm{m}$ & $\mathrm{AK}$ & 5 & 6 & 1 \\
\hline o & $\mathrm{AL}$ & 0 & 0 & 1 \\
\hline $\mathrm{v}$ & $\mathrm{AM}$ & 0 & 0 & 1 \\
\hline $\mathrm{v}$ & $\mathrm{AN}$ & 0 & 0 & 1 \\
\hline $\mathrm{v}$ & $\mathrm{AO}$ & 0 & 0 & 1 \\
\hline
\end{tabular}

